\title{
Small Cell Carcinoma of Urinary Bladder: Analysis from a Tertiary Cancer Care Center of India
}

\begin{abstract}
Context: Small cell cancer of the urinary bladder. Aims: Small cell carcinoma of the bladder is a rare histological subtype, which is particularly aggressive and global literature available describing this entity is sparse. This review of our database was to evaluate clinicopathological and survival outcomes of these patients. Subjects and Methods: The present study was a retrospective analysis of patients with small cell bladder cancer for past 6 years at Rajiv Gandhi Cancer Institute and Research Center, New Delhi. Results: Most of the patients in our study presented with limited stage disease. The overall survival and disease-free survival (DFS) was $49 \%$ and $51.07 \%$ at 2 years, respectively. Preoperative chemotherapy with surgical resection has shown significant survival and DFS benefit. Stage at presentation also affected the survival and DFS though it did not reach statistical significance. Conclusions: Small cell bladder cancer is a rare disease with dismal prognosis. Multimodality treatment with neoadjuvant chemotherapy should be the preferred treatment for limited stage disease.
\end{abstract}

Keywords: India, neuroendocrine carcinoma, small cell bladder carcinoma

\section{Introduction}

Urinary bladder is rarely affected by small cell carcinomas. These are poorly differentiated neuroendocrine carcinomas that are clearly distinct from urothelial carcinomas and their biological behavior is more similar to small cell lung cancer. This entity was first described in 1981 by Cramer et al. and after that only few case series and reports have been published in literature. ${ }^{[1]}$ Recent Surveillance, Epidemiology, and End Results database analysis of 642 small cell bladder cancer patients shown rise in the incidence of small cell bladder cancer from $0.3 \%$ to $0.6 \%$ of all bladder cancer cases with approximately 500 new cases per year, which corresponds to 0.14 cases per 100,000 people. ${ }^{[1,2]}$ Small cell cancer of bladder has poor prognosis and owing to their rarity; there are no specific treatment guidelines described for their effective management. ${ }^{[1,2]}$ Here, in this article, we are presenting our experience with this rare cancer from a tertiary care oncology center in Northern India in terms of clinicopathological profile of patients and survival outcomes. To the best of our

This is an open access journal, and articles are distributed under the terms of the Creative Commons Attribution-Non Commercial-ShareAlike 4.0 License, which allows others to remix, tweak, and build upon the work non-commercially, as long as appropriate credit is given and the new creations are licensed under the identical terms.

For reprints contact: reprints@medknow.com knowledge, the present study is largest and only series describing comprehensive management of small cell bladder cancer.

\section{Subjects and Methods}

The present study is a retrospective review of the data from January 2011 to June 2016. During this study, totally, 1838 cases of carcinoma bladder were evaluated and 20 patients were selected for analysis, which were pathologically proven cases of small cell cancer of bladder. We reviewed and analyzed our computer-based database of patients diagnosed with small cell bladder cancer pertaining to demography, clinicopathological characteristics, treatment received and their follow-up. The patients who were lost to follow-up before completion of planned treatment were excluded from this study. One patient who underwent upfront surgery and died on postoperative day 3 due to pulmonary embolism was excluded from survival analysis. Final survival analysis included a total of 19 patients.

We analyzed disease-free survival (DFS) and overall survival (OS) in relation to stage of the disease, timing of chemotherapy, and histopathological type (pure and mixed);

\footnotetext{
How to cite this article: Ram D, Rajappa SK, Babu Koyyala VP, Chatterjee S, Bhakuni YS, Shukla $\mathrm{H}$, et al. Small cell carcinoma of urinary bladder: Analysis from a tertiary cancer care center of India. Indian J Med Paediatr Oncol 2018;39:326-30.
}

\author{
Dharma Ram, \\ Suhas Kodasoge \\ Rajappa, \\ Venkata Pradeep \\ Babu Koyyala ${ }^{1}$, \\ Smaranjeet \\ Chatterjee ${ }^{1}$, \\ Yogendra Singh \\ Bhakuni, \\ Himanshu Shukla, \\ Amitabh Singh ${ }^{2}$, \\ Sudhir Rawal'
}

Departments of Surgical Oncology, ' Medical Oncology and ${ }^{2}$ Uro-Oncology, Rajiv Gandhi Cancer Institute and Research Centre, New Delhi, India
Address for correspondence: Dr. Dharma Ram, Rajiv Gandhi Cancer Institute and Research Centre, New Delhi - 110 085, India. E-mail: drdharmapoonia@ gmail.com

\section{Access this article online}

Website: www.ijmpo.org

DOI: 10.4103/ijmpo.ijmpo_30_17 Quick Response Code:

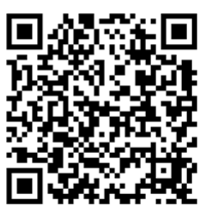


plotted Kaplan-Meier survival curves and compared with log-rank test.

\section{Results}

\section{Patient characteristic}

The demographic and clinicopathological details of all twenty patients are shown in Table 1 . The mean age of presentation was 60 years (range 33-79). About $80 \%$ of patients were male while rest $20 \%$ were female. $60 \%$ of the patients had a history of smoking while one had family history of carcinoma bladder. No other identifiable risk factor was noted in other patients. Hematuria was the presenting symptom in the majority of the patients $(16 / 20)$. Thirteen $(65 \%)$ of our patients were pure small cell while rest $35 \%$ had mixed small cell-urothelial carcinoma. Fifteen of the patients $(75 \%)$ were diagnosed as limited stage disease while $25 \%$ were extensive stage disease by Veteran's administration staging. ${ }^{[3]}$ In this study, the majority of the patients were diagnosed in stage $3(40 \%)$, while two patients were classified as stage 4 by virtue of pathological node positivity. Five $(25 \%)$ of our patients presented as metastatic disease up front with lung, liver, and bones and mediastinal nodal disease as the sites. None of the patients had brain metastasis at presentation.
All five received combination chemotherapy. Two patients from the metastatic group received palliative hemostatic radiation therapy and two received prophylactic cranial irradiation (PCI).

Among the fifteen patients with limited stage disease, twelve of the patients underwent primary surgical resection, and three received neoadjuvant chemotherapy (NACT). None of the patients received definitive or adjuvant radiotherapy. Robotic radical cystectomy was offered to all the patients, but three refused for robotic approach, hence taken for open radical cystectomy. One of the patients underwent total exenteration in view of rectal fixity. All withstood surgery well and manageable surgical complications. Adjuvant chemotherapy was offered to all the patients however two patients declined. Adjuvant treatment was not delayed due to surgical morbidity. One of the patients (Stage 3) succumbed to pulmonary embolism during the early postoperative period and was ruled out from survival analysis [Table 2].

\section{Survival details}

Mean duration of follow-up was 14.2 months (6-24 months). During this follow-up, 7 patients were disease free while 5 were alive with disease and rest 7 patients died due to the disease. The median survival was

\begin{tabular}{|c|c|c|c|c|c|c|c|c|c|c|c|}
\hline Age/sex & $\begin{array}{l}\text { Chief } \\
\text { complaints }\end{array}$ & ASA & $\begin{array}{l}\text { Risk } \\
\text { factor }\end{array}$ & $\begin{array}{c}\text { Family history } \\
\text { of cancer }\end{array}$ & $\begin{array}{c}\text { VA } \\
\text { stage }\end{array}$ & $\begin{array}{l}\text { TNM } \\
\text { stage }\end{array}$ & $\begin{array}{l}\text { Treatment } \\
\text { protocol }\end{array}$ & Surgery & RT & CT & PCI \\
\hline $66 /$ male & Hematuria & 1 & Smoking & No & LD & T2N0 & $\mathrm{RC} \rightarrow \mathrm{ACT}$ & RARC & No & Eto + Carb & No \\
\hline 79/female & Hematuria & 1 & No & No & LD & T2N0 & $\mathrm{RC} \rightarrow \mathrm{ACT}$ & RARC & No & No & No \\
\hline 59/male & Hematuria & 1 & Smoking & No & LD & T3N0 & $\mathrm{RC}$ & RARC & No & - & No \\
\hline $64 /$ female & Hematuria & 2 & No & No & LD & T4aN0 & $\mathrm{RC} \rightarrow \mathrm{ACT}$ & RARC & No & Eto + Carb & No \\
\hline 49/male & Hematuria & 3 & Smoking & No & LD & yT3aN2 & $\mathrm{NACT} \rightarrow \mathrm{RC}$ & RARC & No & Gem + Carb & No \\
\hline $34 /$ male & $\begin{array}{l}\text { Incidental } \\
\text { bladder mass }\end{array}$ & 3 & No & No & LD & yT4aN0 & $\mathrm{NACT} \rightarrow \mathrm{RC}$ & Exenteration & No & Eto + Cis & No \\
\hline $66 /$ male & Hematuria & 1 & No & No & ED & $\begin{array}{l}\text { Lung } \\
\text { Bone }\end{array}$ & $\mathrm{CT}$ & - & $\begin{array}{l}\text { Palliative } \\
\text { hemostatic }\end{array}$ & Gem + carb & Yes \\
\hline $48 /$ male & Hematuria & 1 & Smoking & No & LD & T2N0 & $\mathrm{RC}$ & - & No & & No \\
\hline $68 /$ male & $\begin{array}{l}\text { Incidental } \\
\text { bladder mass }\end{array}$ & 1 & Smoking & No & ED & Bone & CT & - & No & Eto + Cis & No \\
\hline $73 /$ male & Hematuria & 4 & Smoking & No & ED & Lung & $\mathrm{CT}$ & - & No & Eto + cis & Yes \\
\hline $33 /$ male & Hematuria & 3 & Smoking & No & LD & T2N0 & $\mathrm{NACT} \rightarrow \mathrm{RC}$ & RARC & No & Eto + Carb & No \\
\hline $60 /$ male & Hematuria & 3 & Smoking & No & ED & Liver & CT & & No & $\mathrm{Gem}+\mathrm{Carb}$ & No \\
\hline $67 /$ male & Hematuria & 2 & No & No & ED & LNs & $\mathrm{CT}$ & & $\begin{array}{l}\text { Palliative } \\
\text { hemostatic }\end{array}$ & Eto + Cis & No \\
\hline $44 /$ male & Hematuria & 1 & Smoking & Yes & LD & T3N0 & $\mathrm{RC} \rightarrow \mathrm{ACT}$ & RARC & No & Eto + Carb & No \\
\hline $62 /$ male & Hematuria & 1 & Smoking & No & LD & T3N0 & $\mathrm{RC} \rightarrow \mathrm{ACT}$ & RARC & No & Eto + Carb & No \\
\hline $70 /$ male & Hematuria & 1 & Smoking & No & LD & T2N0 & $\mathrm{RC} \rightarrow \mathrm{ACT}$ & RARC & No & Eto + Cis & No \\
\hline 77/female & Irritative LUTS & 1 & No & No & LD & T4aN0 & $\mathrm{RC} \rightarrow \mathrm{ACT}$ & ORC & No & Eto + Cis & No \\
\hline $65 /$ male & Hematuria & 2 & Smoking & No & LD & T4aN1 & $\mathrm{RC} \rightarrow \mathrm{ACT}$ & RARC & No & Gem + Carb & No \\
\hline 59/male & Irritative LUTS & 2 & No & No & LD & T3N0 & $\mathrm{RC} \rightarrow \mathrm{ACT}$ & RARC & No & Gem + Carb & No \\
\hline $71 /$ male & Hematuria & 2 & Smoking & No & LD & T4aN0 & $\mathrm{RC}$ & RARC & No & - & No \\
\hline
\end{tabular}

ASA - American Society of Anesthesiologists score; ACT - Adjuvant chemotherapy; Carbo - Carboplatin; Cis - Cisplatin; Eto - Etoposide; ED - Extensive stage disease; LD - Limited stage disease; VA - Veterans administration staging; PCI - Prophylactic cranial irradiation; NACT=Neoadjuvant chemotherapy; RC - Radical cystectomy; RARC - Robot-assisted radical cystectomy; RT - Radiotherapy; LUTS - Lower urinary tract symptoms; CT - Chemotherapy 
18.5 months (standard deviation [SD] 1.56, 15.51-21.64), while median DFS was 17.1 months (SD-2.04,
13.13-21.14). OS at 2 years was $49 \%$ and DFS at 2 years was 51\% [Table 3 and Figure 1]. Medline search was with

\begin{tabular}{|c|c|c|c|c|c|}
\hline Serial number & Stage & Last follow-up duration & Status at last follow up & Site of recurrence & Duration to recurrence \\
\hline 1 & 2 & 24 months & Disease free & - & \\
\hline 2 & 2 & 24 months & Disease free & - & \\
\hline 3 & 3 & $*$ & Dead & - & \\
\hline 4 & 3 & 20 months & Disease free & - & \\
\hline 5 & $4(\mathrm{~N}+\mathrm{ve})$ & 15 months & Disease free & - & \\
\hline 6 & 3 & 19 months & Disease free & - & \\
\hline 7 & Metastatic & 11 months & Dead & - & \\
\hline 8 & 2 & 8 months & Dead & Retroperitoneal mass & 5 months \\
\hline 9 & Metastatic & 20 months & Alive with disease & - & \\
\hline 10 & Metastatic & 6 months & Alive with disease & - & \\
\hline 11 & 2 & 6 months & Disease free & - & \\
\hline 12 & Metastatic & 9 months & Dead & - & \\
\hline 13 & Metastatic & 11 months & Dead & - & \\
\hline 14 & 3 & 16 months & Alive with disease & Pelvic mass & 12 months \\
\hline 15 & 3 & 19 months & Dead & Lung & 11 months \\
\hline 16 & 3 & 12 months & Alive with disease & Liver & 11 months \\
\hline 17 & 2 & 10 months & Disease free & - & \\
\hline 18 & $4(\mathrm{~N}+\mathrm{ve})$ & 16 months & Dead & Brain, bone, liver & 8 months \\
\hline 19 & 3 & 10 months & Alive with disease & Pelvic mass & 9 months \\
\hline 20 & 3 & 15 months & Dead & Liver, LNs & 11 months \\
\hline Mean duration & - & 14.26 months & $\begin{array}{l}\text { Dead: } 5 \\
\text { Alive with disease: } 7 \\
\text { Disease free: } 7\end{array}$ & - & 11.16 months \\
\hline
\end{tabular}

*This particular patient suffered from early postoperative death due to pulmonary embolism and excluded from final survival analysis. LNs - Lymph nodes

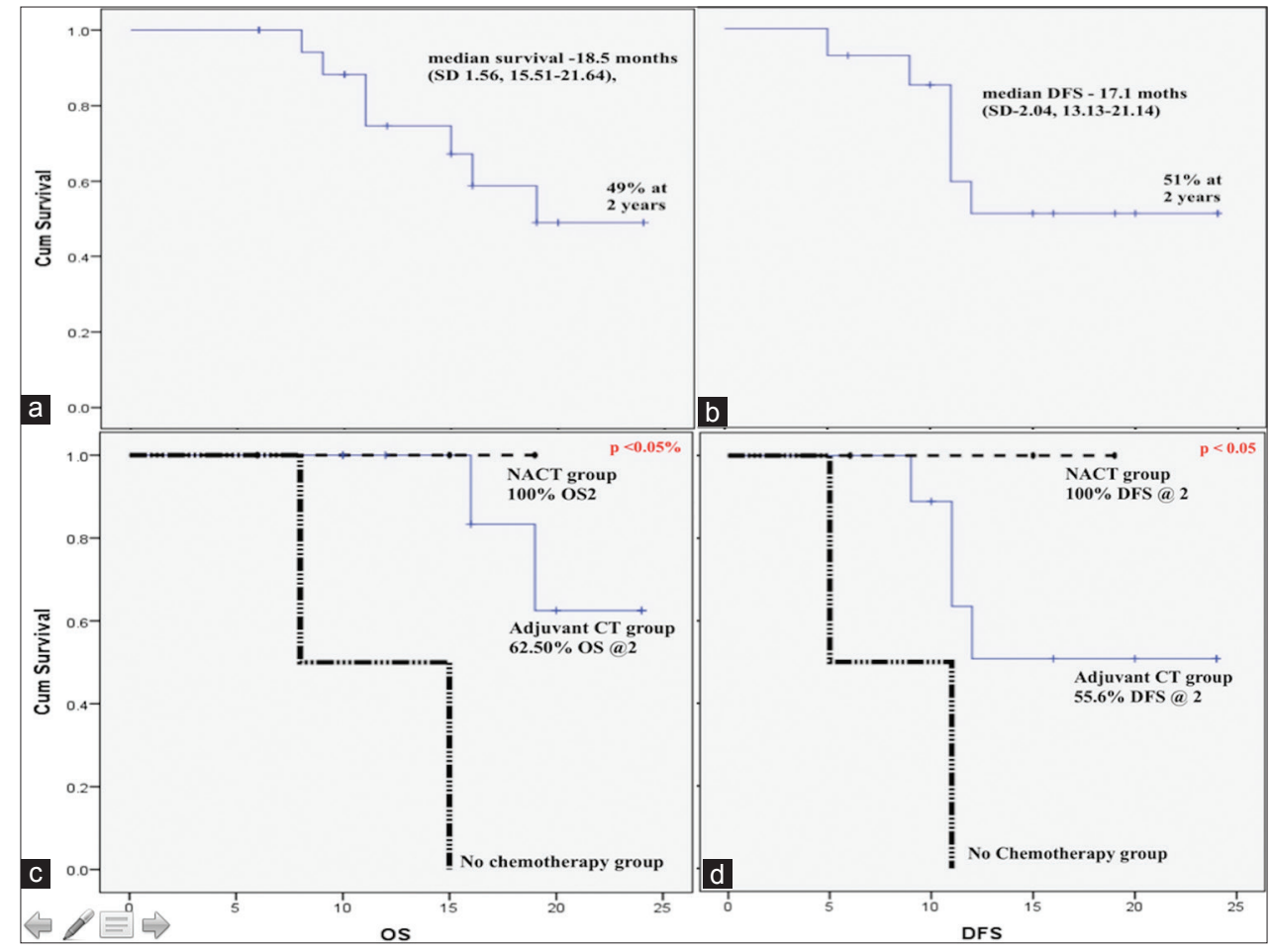

Figure 1: Survival characteristics with Kaplan-Meier survival curves. Overall survival of the all the patients (a) and in relation to timing of chemotherapy (b); disease-free survival of the all the patients (c) and in relation to timing of chemotherapy (d) 


\begin{tabular}{|c|c|c|c|c|c|}
\hline Variable & $n$ & Status at last follow-up & OS at 2 years $(\%)$ & $n$ & DFS at 2 years $(\%)$ \\
\hline \multirow[t]{4}{*}{ All patients } & 19 & 7 Dead & 49 & - & - \\
\hline & & 5 AWD & & & \\
\hline & & $7 \mathrm{DF}$ & & & \\
\hline & \multicolumn{4}{|c|}{ Survival outcomes of the patients in relation to histology type $(P>0.05)$} & \\
\hline Pure SCC & 13 & & 49.1 & - & - \\
\hline \multirow[t]{2}{*}{ Mixed SCC with UC } & 7 & & 48.4 & & - \\
\hline & \multicolumn{4}{|c|}{ Survival outcomes of limited disease in relation to TNM stage $(P>0.05)$} & \\
\hline \multirow[t]{3}{*}{ Limited disease } & 14 & 4 Dead & 56.26 & 14 & 51.07 \\
\hline & & 3 AWD & & & \\
\hline & & $7 \mathrm{DF}$ & & & \\
\hline \multirow[t]{2}{*}{ Stage 2} & 5 & 1 Dead & 75 & - & 80 \\
\hline & & $4 \mathrm{DF}$ & & & \\
\hline \multirow[t]{3}{*}{ Stage 3} & 7 & 2 Dead & 53.3 & - & 28.57 \\
\hline & & 3 AWD & & & \\
\hline & & $2 \mathrm{DF}$ & & & \\
\hline \multirow[t]{3}{*}{ Stage $* 4(\mathrm{LN}+\mathrm{ve})$} & 2 & 1 Dead & 0 & - & 50 \\
\hline & & $1 \mathrm{DF}$ & & & \\
\hline & \multicolumn{4}{|c|}{ Survival outcomes of limited disease in relation to $\mathrm{CT}(P<0.05)$} & \\
\hline Received NACT & 3 & $3 \mathrm{DF}$ & 100 & - & 100 \\
\hline \multirow[t]{3}{*}{ Received ACT } & 9 & 2 Dead & 62.50 & - & 55.6 \\
\hline & & 3 AWD & & & \\
\hline & & $4 \mathrm{DF}$ & & & \\
\hline No CT & 2 & 2 Dead & 0 & - & 0 \\
\hline Stage 4 (metastatic)/ & 5 & 3 Dead & 25 & - & - \\
\hline $\mathrm{ED}$ & & 2 AWD & & & \\
\hline
\end{tabular}

*Stage 4 (LNs+ve), patient with pN+ on final histology. AWD - Alive with disease; DFS - Disease-free survival; DF - Disease free; OS - Overall survival; ED - Erectile dysfunction; ACT - Adjuvant chemotherapy; NACT - Neoadjuvant chemotherapy; SCC - Squamous cell carcinoma; UC - Urothelial carcinoma; CT - Chemotherapy; LNs - Lymph nodes

key word of small cell cancer of the bladder, high-grade neuroendocrine cancer of bladder, poorly differentiated bladder cancer, India, results did not demonstrate any series published with these key words.

Among limited disease group, 7 patients were disease free at last follow-up while 4 of them died of the disease and rest 3 were alive with disease. Three (21.4\%) patients developed locoregional recurrence ( 2 pelvic masses and one retroperitoneal nodal disease), while rest $28.6 \%$ (4) patients developed distant metastasis on follow-up out of which one recurred in the brain. The mean duration to recurrence was 11.3 months and mean duration to death was 5.5 months from the time of recurrence. OS at 2 years was $56.26 \%$ while DFS was $51.07 \%$. On univariate analysis by $\log$ rank test shown significant survival and DFS advantage using NACT. Two patients who did not received chemotherapy shown poorest of survival and died of the disease before last follow-up. OS for stage 2, 3, and $4(\mathrm{~N}+\mathrm{ve})$ were $75 \%, 53.3 \%$, and $0 \%$, respectively $(P>0.05 \%)$, while DFS were $80 \%, 28.5 \%$, and $50 \%$, respectively $(P>0.05)$. These results did not reach to significance level. The probable explanation may be limited number of individuals.

Among extensive stage patients, only 2 patients were alive while rest 3 succumbed to the disease at median follow-up of 12.4 months and median duration of death was 10.3 months.

\section{Discussion}

Small cell bladder cancer is an uncommon histological type as reported in literature and it is evident in our study also. It accounts for approximately $1 \%$ of bladder cancer cases. This current series on small cell bladder cancer is the largest to be reported from India to the best of our knowledge. Pertaining to the same disease, there are few retrospective single institute series or case reports across the globe..$^{[1-4]}$

The World Health Organization proposed the revised classification of neuroendocrine tumors in 2016. The recent improvement in understanding of molecular pathology and disease behavior might help in treatment innovations and eventually translate into better survival. ${ }^{[5]}$

The age of presentation, gender distribution, and association with smoking in our study were in alignment with the reported literature. ${ }^{[1-4]}$ The survival outcomes of the patients in relation to pure or mixed histology is reported variably as prognostic factor of outcome in existing literature. We did not find its role as a prognostic variable as shown by few series. ${ }^{[5,6]}$ Few recent series has shown inferior survival in patients with pure histology. ${ }^{[7,8]}$ Our results are similar 
to existing literature in relation to stage of presentation, site of metastasis, and proportion of cases with brain metastasis. ${ }^{[4,7,9]}$ None of the patients had brain metastasis at presentation; while one $(5.26 \%)$ developed brain metastasis on follow-up. Two of our patients received PCI even though its role on preventing brain metastasis not well defined.

The median survival has been reported between 10 and 20 months with 5\%-20\% 5-year OS..$^{[1,2,10]}$ Our results are in concordance with existing literature. The management of limited disease has been historically defined as combination chemotherapy with radical surgery, however, few series reported the role of bladder preservation approaches with chemotherapy and radiotherapy. We did not offer any of the patient bladder preservation with radiotherapy, but this may be vital option for the patients who are high-risk surgical candidate or declines surgery. ${ }^{[3,7,11,12]}$ Fifteen $(75 \%)$ of our patients presented in early stage disease and were treated with curative intent. The OS and DFS are inferior in extensive disease than limited disease but did not reach to statistical significance, and the results are similar to the data reported in literature ${ }^{[1,2,10]}$ The role of chemotherapy and more so in preoperative setting has been shown to improve the OS and DFS in recent literature including a phase II study from MD Anderson Cancer Center. ${ }^{[10,12]}$ We observed significant benefit in OS and DFS with neoadjuvant chemotherapy as compared to adjuvant chemotherapy while worst survival was seen in the patients who did not receive chemotherapy. This highlights the importance of incorporation of chemotherapy in the early part of management. One notable series came from India where Nabi et al. described their experience of 11 patients over the period 10 years. ${ }^{[13]}$ Seven of their patients had surgery followed by chemotherapy, while rest 4 managed with chemoradiotherapy. The median survival was 16.5 months (6-30 months), which is comparable with our series, though we used surgical resection in all the patients. ${ }^{[13]}$

The limitations of this study are its retrospective nature, limited duration of follow-up, small number of individuals and only surgical bimodality being tested and not comparing with radiotherapy.

\section{Conclusions}

Small cell bladder cancer is an uncommon disease entity. Overall prognosis is dismal despite aggressive multimodality. NACT followed by surgical resection has the best results and should be the standard of care for limited disease patients. Extensive disease patients should be managed with a combination of chemotherapy. Role of PCI and bladder preservation are yet to be defined. For further characterization and management outcomes data from further randomized control trials are needed.

\section{Financial support and sponsorship}

Nil.

\section{Conflicts of interest}

There are no conflicts of interest.

\section{References}

1. Thota S, Kistangari G, Daw H, Spiro T. A clinical review of small-cell carcinoma of the urinary bladder. Clin Genitourin Cancer 2013;11:73-7.

2. Koay EJ, Teh BS, Paulino AC, Butler EB. A surveillance, epidemiology, and end results analysis of small cell carcinoma of the bladder: Epidemiology, prognostic variables, and treatment trends. Cancer 2011;117:5325-33.

3. Moretto P, Wood L, Emmenegger U, Blais N, Mukherjee SD, Winquist $\mathrm{E}$, et al. Management of small cell carcinoma of the bladder: Consensus guidelines from the Canadian Association of Genitourinary Medical Oncologists (CAGMO). Can Urol Assoc J 2013;7:E44-56.

4. Chhabra S, Hegde P, Singhal P. Primary small cell carcinoma of the urinary bladder - Mini-review of the literature. Asian Pac J Cancer Prev 2012;13:3549-53.

5. Kouba E, Cheng L. Neuroendocrine tumors of the urinary bladder according to the 2016 World Health Organization classification: Molecular and clinical characteristics. Endocr Pathol 2016;27:188-99.

6. Cheng L, Pan CX, Yang XJ, Lopez-Beltran A, MacLennan GT, Lin $\mathrm{H}$, et al. Small cell carcinoma of the urinary bladder: A clinicopathologic analysis of 64 patients. Cancer 2004;101:957-62.

7. Pasquier D, Barney B, Sundar S, Poortmans P, Villa S, Nasrallah $\mathrm{H}$, et al. Small cell carcinoma of the urinary bladder: A Retrospective, multicenter rare cancer network study of 107 patients. Int J Radiat Oncol Biol Phys 2015;92:904-10.

8. Choong NW, Quevedo JF, Kaur JS. Small cell carcinoma of the urinary bladder. The mayo clinic experience. Cancer 2005; 103:1172-8.

9. Bex A, Sonke GS, Pos FJ, Brandsma D, Kerst JM, Horenblas S, et al. Symptomatic brain metastases from small-cell carcinoma of the urinary bladder: The netherlands cancer institute experience and literature review. Ann Oncol 2010;21:2240-5.

10. Lynch SP, Shen Y, Kamat A, Grossman HB, Shah JB, Millikan RE, et al. Neoadjuvant chemotherapy in small cell urothelial cancer improves pathologic downstaging and long-term outcomes: Results from a retrospective study at the MD Anderson cancer center. Eur Urol 2013;64:307-13.

11. Available from: http://www.nccn.org/professionals/physician_gls/ pdf/bladder.pdf. [Last accessed on 2017 Jan 16].

12. Siefker-Radtke AO, Kamat AM, Grossman HB, Williams DL, Qiao W, Thall PF, et al. Phase II clinical trial of neoadjuvant alternating doublet chemotherapy with ifosfamide/doxorubicin and etoposide/cisplatin in small-cell urothelial cancer. J Clin Oncol 2009;27:2592-7.

13. Nabi G, Singh I, Ansari MS, Sharma MC, Dogra PN. Primary small cell neuroendocrine carcinoma of urinary bladder: An uncommon entity to be recognized. Int Urol Nephrol 2001;33:637-40. 